\title{
A qualitative study of the intrinsic motivation of physicians and other health professionals to teach
}

\author{
Lukas Lochner ${ }^{1}$, Heike Wieser ${ }^{2}$, Maria Mischo-Kelling² \\ ${ }^{1}$ Teaching Support Office, Claudiana- College of Health- Care Professions, Italy \\ ${ }^{2}$ Research Unit, Claudiana - College of Health - Care Professions, Italy \\ Correspondence: Lukas Lochner, Claudiana- College of Health - Care Professions, Via Lorenz Böhler 13, 39100 \\ Bolz no/Bozen, Italy. E-Mail: lukas.lochner@claudiana.bz.it
}

\begin{abstract}
Objectives: To explore the intrinsic motivation of physicians and other health professionals to teach.

Methods: Qualitative data from in-depth interviews were thematically analysed. A purposive opportunity sample of eight physicians and other healthcare professionals employed by our institution to teach Bachelor-level courses in health care participated in the study.

Results: Four themes that suggested an internal desire to teach were identified: 1 . Interest in the subject matter; 2 . Interest in the students' development; 3. Interest in establishing rapport; and 4. Importance of students' feedback. Participants reported a strong interest in their field of practice and the subject matter of their instruction; they enjoyed their own learning while teaching. They stated an internal desire to impart knowledge for its own sake and
\end{abstract}

showed concern for the effectiveness of their teaching. They also described a strong desire to establish teacher-student rapport and reported that feedback from students was crucial in maintaining their motivation to teach.

Conclusions: This study has addressed a topic where research-based knowledge is limited: the intrinsic motivation to teach. The findings contribute to a deeper understanding of the internal desire of health professionals to engage in teaching and constitute a starting point for developing further research to explore these processes more fully. We believe that a better understanding of the factors that enhance a teacher's motivation can help to optimise educational environments.

Keywords: Faculty development, health professionals, qualitative study, self-determination theory, teacher motivation

\section{Introduction}

Although there is evidence that a teacher's motivation to teach has a direct impact on student enthusiasm for the subject and level of achievement, ${ }^{1}$ research in this area is limited and the topic of teacher motivation is regarded as an 'overlooked area'. ${ }^{2}$ Moreover, research literature is predominantly focused on primary and secondary education. Pertinent handbooks of higher education teaching regularly discuss student motivation, while teacher motivation is not explored. $^{3-6}$

Studies in medical education examined motives and incentives to teach as well as the barriers encountered. ${ }^{7-19}$ In the light of the recent trend towards more generalist teach- ing, most of these studies aimed at improving recruitment of (volunteer) community physicians..$^{8-12,14,15,17,19}$ The predominant qualitative research method used is the questionnaire survey, ${ }^{7,9-11,13-16,18,19}$ while focus groups ${ }^{12}$ and semistructured interviews ${ }^{17}$ are less frequently employed. The satisfaction derived from teaching is often a minor consideration within the published literature with the main focus lying elsewhere. ${ }^{8}$ Overall these studies reveal that physicians and other health professionals regard internal factors described as 'enjoyment of teaching ${ }^{8,9,14,15}$, 'fulfilment as a teacher'19, 'feeling intrinsic satisfaction'12, 'intellectual satisfaction'16, 'self-expression'13, 'helping others' ${ }^{\prime 13}$, 'altruistic 
reasons ${ }^{18}$, and 'personal satisfaction"11 - as the key motivators for teaching, while financial compensation and other external factors ranked far lower. To the best of our knowledge, no research has explicitly examined these internal factors further. A better understanding of the factors affecting a teacher's motivation to teach could help us in encouraging health professionals to engage in and appreciate the value of teaching.

\section{Theoretical frame}

Ryan and Deci's Self-determination Theory $(S D T)^{20}$ is a major theoretical influence in the psychology of motivational processes and its utility and application in medical education have been strongly advocated. ${ }^{21}$ SDT offers a well-established framework that can assist in exploring what motivates health professionals to teach and what drives them towards improving their teaching performance. Ryan and Deci differentiate between 'extrinsic motivation', which refers to doing something because it leads to a separable outcome, and 'intrinsic motivation', which refers to doing something for the inherent satisfaction of the activity itself. ${ }^{20}$ They further develop this concept by placing extrinsic motivation on a continuum between external regulation (e.g. an activity is done to increase one's salary) and integrated regulation (e.g. an activity is seen as one's professional role), a distinction that relies on the degree of 'internalisation' of experiences, values, and attitudes into the intrinsic aspects of oneself. If sufficiently 'internalised', extrinsically motivated actions become self-determined. ${ }^{20}$ The most autonomous form of extrinsic motivation is theoretically distinguishable from pure intrinsic motivation, which represents the prototype of self-determined behaviour, but in practice this difference is not relevant. ${ }^{21}$ According to SDT, this operation of integration, called the organismic integration process, is fostered by three innate psychological needs: competence (i.e. feeling efficacious and having a sense of accomplishment), autonomy (i.e. experiencing oneself as the determinant of one's behaviour), and relatedness (i.e. feeling a sense of belonging with other individuals, work groups, or culture).$^{22}$ It has been fairly consistently shown that self-determined behaviour is associated with higher satisfaction and more effective performance. $^{23}$

As elaborated above, the activity of teaching it seems, is rarely undertaken for high salaries or social recognition, but is (more so than other behavioural domains) associated with an expectation of satisfaction: there appears to be an internal desire to impart knowledge and to educate people. ${ }^{1}$ However, it is only partially understood as to the exact nature of the intrinsic motivation to teach.

\section{Aims}

We designed a qualitative study to investigate the intrinsic motivation of physicians and other health professionals to engage in teaching in health professional education and to provide an interpretive account of the experiences of these professionals that would enhance evidence based professional development.

\section{Methods}

\section{Curricular context}

At the College of Health-Care Professions in Bolzano/Bozen, Italy, physicians and other health professionals are employed to teach various Bachelor-level courses in health-care (e.g. nursing sciences, physiotherapy, occupational therapy, midwifery). Teachers are content experts in their respective professional fields with no formal pedagogical education as often their employment in health services relegates their educational engagement to an ancillary activity. The predominant method of teaching is the traditional lecture to groups ranging from 20 to 150 students. Teaching is formally evaluated by students through a questionnaire completed at the end of each course. The institution offers free workshops and seminars in teaching skills where participation is voluntary.

\section{Study approach}

To ascertain motivational processes and dynamics in teaching, qualitative approaches are considered to be more effective than quantitative techniques. ${ }^{1}$ To achieve a holistic understanding of the participants' personal feelings and experiences, in-depth interviews were the preferred method of data collection. Participants were selected from a presumably highly-motivated group of teachers who participated in one of the voluntary pedagogical seminars offered by our institution. None of the authors were involved in the organisation and conduction of these seminars. This purposive selective sampling process was based on the intention of accessing 'key informants' from a self-selecting group of highly-motivated individuals.

\section{Subject recruitment}

We defined four inclusion criteria for participating teachers: 1. They had to be teaching at our institution; 2 . Their principal occupation needed to be in the health-care industry; 3 . They had to have participated in at least one pedagogical seminar offered by our institution; and, 4 . They needed to speak German language fluently (teaching at our institution is conducted in German and Italian). We sent letters to all twelve health professionals who matched these criteria. Eight of the recipients responded and agreed to participate in the study. All of them were subsequently invited for a private interview. Four health professionals did not respond to the letters for unknown reasons. The scientific committee of the institution approved the study and participants gave written informed consent. Pseudonyms were assigned for interviews and all identifying information was suppressed in the transcripts. 


\section{Data collection}

The interviews were initiated with the open-ended question: 'What motivates you to teach?', aimed at exploring the interviewee's motivation to engage in teaching in health professional education. Other questions included: 'How do you feel while teaching?', 'Can you describe a very motivating teaching experience?', and/or 'Can you describe a very demotivating teaching experience?'. When felt necessary, interviewees were encouraged to describe their thoughts and perspectives more deeply using clarification questions like: 'Can you tell me more about what you mean by that?', 'Can you explain this in other words?', 'Can you give us an example?', and/or 'That is interesting! Can you explain in more detail?'. In case participants started to talk about extrinsic rewards, e.g. financial compensation, the interviewers attempted to steer the interview back to focusing on the satisfaction that derives from the activity of teaching. Great care was taken to ensure that interviewees did not feel judged or evaluated. The interviews were conducted by two researchers (LL, HW); and were audio-recorded and transcribed verbatim. Participants were given the opportunity to verify their transcripts. One participant made use of this and clarified sections in the transcript. Basic demographic data was collected.

\section{Data analysis}

For data analysis, some techniques derived from grounded theory research were used. ${ }^{24}$ The first three transcripts were inductively analysed by two researchers (LL, HW) using a line-by-line, open-coding strategy to establish an initial code system. During the open-coding process, data was broken apart and codes were created identifying concepts to stand for the data (there was no prior definition of codes with subsequent allocation of data). At the same time the emerging concepts were related to each other (a process referred to as axial coding). After the initial code system was established, the remaining transcripts were coded independently by all three researchers. In applying the technique of constant comparison, statements from one transcript were compared to either similar or different statements in the other transcripts in order to group and analyze the perspectives on the central issues. In case new codes emerged, they were compared between the researchers to maintain a common code structure. This was done using consensus between the three researchers. The following organization of codes into larger clusters, which required a repeated review of the transcripts, led to identification of commonly agreed themes and subthemes.

\section{Results}

\section{Participants and demographics}

The eight participants were four doctors (one surgeon, one pathologist and two specialists in hygiene and preventive medicine), two nurses, a dietician, and a biologist. They were all hired by our institution for teaching various classes in the Bachelor courses of nursing sciences, physiotherapy, occupational therapy, midwifery, laboratory techniques, nutritional sciences, speech therapy, and radiologic technology. Four of the participants were male, four were female. Seven of them were working on a full time basis in the healthcare industry, one participant worked $50 \%$-part time. Six of the participants indicated more then ten years of teaching experience, one participant had five years of teaching experience and one participant had less than three years of teaching experience. Interviews lasted from thirty to fifty minutes, with the average being forty minutes.

\section{Identified themes}

Four themes were identified that suggested an internal motivation to teach. They were subdivided into two or three sub-themes. The following description of the themes is a summary of what the participants expressed, illustrated by selected quotations, translated as closely as possible from German to English to keep the original content intact.

\section{Interest in the subject matter}

The first theme highlights the enthusiasm of the health professionals for their field of practice and the enjoyment of personal learning while teaching.

\section{Enthusiasm for one's discipline}

Participants described enthusiasm for their field of practice as essential to their enjoyment of teaching. One participant said:

\footnotetext{
"You notice right away if a teacher is in love with his subject matter or not [...] If you start teaching the same contents over and over again then something is wrong, you have lost the interest in your subject matter, and, therefore, in teaching." (Doctor, male, full time, $>10$ years teaching)
}

\section{Desire to gain new insights into the subject matter through teaching}

Participants experienced satisfaction from their own learning process while teaching. One participant stated:

"I am deeply convinced that there is no better method to understand something than teaching it to someone else. Every time I explain something, even if done so before, I learn it better." (Nurse, male, full time, $>10$ years teaching)

Participants attributed this learning to the effect of repetition and to the opportunity to further elaborate on the material:

\footnotetext{
"When I need to prepare material for teaching, I need to organise my knowledge in a different way. I need to abstract, to schematise, and to synthesise." (Nurse, male, full time, >10 years teaching)
} 
Being exposed to a group of students during teaching constitutes an extra challenge to the knowledge base of the teacher. One participant explained this:

"Of course, I have a lot of professional experience, but there are questions [from the students] where I first need to look things up. And that is good for me." (Doctor, female, full time, $>10$ years teaching)

Another participant attributed the gaining of new insights to the effect of viewing the material from a clinical perspective:

"[While I prepared a lecture,] I had a lot of 'Aha!' moments that I missed as a student. Probably because I didn't see the clinical correlations." (Doctor, male, full time, $>10$ years teaching)

Nearly all participants perceived teaching as a welcome opportunity to keep up with an ever-expanding body of knowledge in their respective field of professional expertise. One participant stated:

"Teaching helps me to retain my theoretical knowledge, to be prepared, to stay up-to-date." (Dietician, female, full time, >10 years teaching)

Most participants explained that their learning through teaching has a beneficial influence on their professional work. One physician said:

\footnotetext{
"At my workplace, things are more complex than what the students need to know. But the fact that every time [when I prepare lectures] I am forced to pick up books and papers again... that always positively influences my daily work." (Doctor, male, full time, $>10$ years teaching)
}

Three participants explained that a teaching assignment forces the professional out of his or her daily routine, which allows for reflecting and critical thinking. One participant stated:

"I believe that it [teaching] is beneficial for your work, because at work you only do the necessary things because of time pressure. [When you teach] you are forced to see other aspects and learn things you wouldn't otherwise approach." (Biologist, female, full time, 5 years teaching)

\section{Desire to set educational priorities in one's discipline}

Participants spoke of their desire to influence the educational objectives of their discipline. Participants stated:

"II want to be involved in the] setting of priorities [in my discipline] because they have practical relevance for that profession." (Doctor, male, full time, $>10$ years teaching)

"I have experienced that certain topics are taught by people who weren't familiar with them. I think that's bad. The topics should be taught only by those who are professionally active in that field [of practise]." (Doctor, female, full time, $>10$ years teaching)

\section{Interest in students' development}

The second theme relates to the enthusiasm for teaching and the satisfaction of seeing the students' progress. Interest in the teaching process is considered a stimulus for the development of effective teaching methods.

\section{Desire to impart knowledge and educate people}

Participants reported the enjoyment of conveying knowledge for its own sake and the pleasure of teaching:

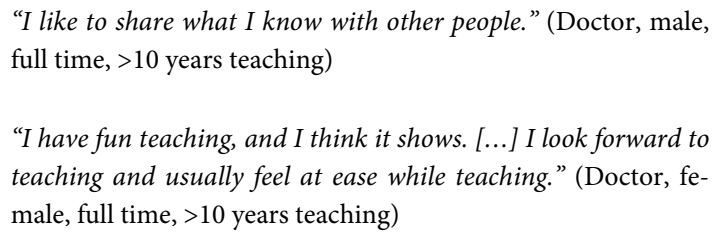

"I like to share what I know with other people." (Doctor, male, full time, $>10$ years teaching)

"I have fun teaching, and I think it shows. [...] I look forward to teaching and usually feel at ease while teaching." (Doctor, female, full time, $>10$ years teaching)

Some participants ascribed their interest in teaching to a fascination with the process of knowledge transfer, which originated from their own experiences as students:

"I had a lot of good teachers [as a student] and some bad ones and I was always fascinated about what makes teaching good teaching. [...] For me, teaching remains a mystery." (Doctor, male, full time, $>10$ years teaching)

\section{Desire to improve one's teaching}

Participants commented that when they recognised a weakness in their teaching process, they experienced a reflective process. They welcomed professional advice as a valuable impetus for self-improvement. Participants said:

\footnotetext{
"I became aware that I can do a lot of things better in my teaching. I didn't feel prepared enough to teach." (Dietician, female, full time, $>10$ years teaching)

"I like to get tips and advice on how I can improve my teaching in order to better communicate the content I want to transmit." (Doctor, female, full time, $>10$ years teaching)

"I would like to get away from the gut-feeling and the students' feedback [to improve my teaching]. I want someone who can tell me how it [the teaching] should be done from a scientific educational point of view." (Doctor, male, full time, $>10$ years teaching)
}

\section{Interest in establishing rapport}

The third theme explores the opportunity to establish interpersonal relationships in the form of teacher-student rapport and contact with young people.

\section{Desire to build interpersonal relationships}

All participants described, in one form or another, the potential to build teacher-student rapport as a very strong teaching motive. Participants said:

"When I have the feeling I can establish, even in this short period of teaching, a small relationship to the students - not to all of 
them, but to most of them - that gives me a lot." (Doctor, female, full time, $>10$ years teaching)

"I enjoy the personal contact [with the students]. When I have the feeling I can establish a relationship ... that's very satisfying for me." (Nurse, male, full time, $>10$ years teaching)

While this teacher-student rapport usually ends at the completion of a course, one participant described the continuation of this relationship through the supervision of thesis papers as being an 'educational highlight', commenting that:

"You have the possibility to continue this [student-teacher] relationship within the framework of a thesis project. This, for me, is the highlight of my educational activity." (Doctor, male, full time, $>10$ years teaching)

In contrast, participants described the demotivating impact of didactic lecturing to large groups of students, local distance to the educational institution and/or restricted course time on their relationship with students:

\begin{abstract}
"Important for me is the personal contact. That's why I like small classes better than large lecture halls." (Doctor, female, full time, $>10$ years teaching)

"When I have to drive to a different city [to teach], I see the students only for four, five or ten days. I cannot establish rapport in that case." (Doctor, male, full time, $>10$ years teaching)
\end{abstract}

\section{Desire to establish contact with young people}

Participants described the possibility of becoming acquainted with the views and opinions of a younger generation as beneficial. They stated that this contact leads to a process of self-reflection and a new perspective of their own ideas and practices. This impact was felt both personally and professionally. Participants said:

\begin{abstract}
"Teaching young students offers me an entry into their world. Until recently I had no contact with this age group at all, they didn't belong to my group of clients [patients]." (Dietician, female, full time, $>10$ years teaching)
\end{abstract}

"There are always critical heads [students] [...] and, effectively, they made me think how things could be done differently." (Doctor, male, full time, $>10$ years teaching)

\section{Importance of students' feedback}

The fourth theme relates to the importance of feeling effective as a teacher in maintaining motivation. This occurs through students' feedback. While the formal questionnaire feedback at the end of the course was described as a valuable tool to improve teaching, the informal, positive feedback from students - immediate and/or delayed - was reported to be a particularly strong motivating factor for teaching.

\section{Interest in immediate feedback from students}

Participants described the attentiveness of students in class and their level of participation, as well as simpler indications such as facial expressions, as being important sources of immediate feedback on their teaching performance. Participants stated:

"I enjoy teaching when I have the impression that they [the students] listen to me." (Nurse, female, part time, <3 years teaching)

"I am enjoying it, when students tell me that they liked it [the lecture]. That gives me a lot." (Doctor, female, full time, $>10$ years teaching)

"After teaching I think about how students responded, how they participated, what they found interesting. The interest they showed gives me satisfaction." (Biologist, female, full time, 5 years teaching)

\section{Interest in delayed feedback from students}

Participants also reported feeling gratified when receiving positive feedback long after the teaching had occurred. Two participants said:

"Meanwhile, a lot of students have entered professional life. [I like it] when you meet them again and they say 'yes, that [the teaching] was great back then'." (Biologist, female, full time, 5 years teaching)

"When you encounter students later in their professional life and they tell you 'today something happened that you taught us back then'... I like that, it is a reward for me, and it's a very positive experience." (Doctor, male, full time, $>10$ years teaching)

Overall, participants explained that receiving positive feedback from students was essential in maintaining the motivation to teach. For example, one participant stated:

"I think you only have fun [teaching] when you get positive feedback [from students]. If that's not the case, you will eventually quit [teaching]." (Nurse, male, full time, $>10$ years teaching)

\section{Discussion}

This study highlights the intrinsic motivation of health professionals to engage in teaching in health professions education. Four themes were identified that suggested an internal desire to teach: interest in the subject matter, interest in students' development, interest in establishing teacher-student rapport, and the importance of students' feedback.

Self-determination Theory (SDT) predicts that teachers will be intrinsically motivated for tasks that evoke feelings of competence. ${ }^{20}$ Competence means feeling effective in the action one performs and is necessary to enhance one's intrinsic motivation to pursue this action. In this study two 
sources of experiencing competence as a teacher emerged: The first one is the teachers' feelings of competence in their fields of practice while lecturing to students, the second one is the need for the teachers to experience satisfaction from the students' development. Being able to help students to progress, however, is more dependent on the educational know-how of the teacher, than on his or her professional expertise. Participation in teacher training courses that give teachers the skills to enhance students' development should therefore be likely to enhance the motivation to teach. Faculty development programs should therefore address educational tools that make students' progress visible to the teacher (e.g. formative assessment techniques).

We believe that teaching is likely to be most effective when the teacher is simultaneously interested in the subject matter and in the students' development. During our study the participants indicated varying degrees of interest in these two factors. It could prove worthwhile to determine the significance of each factor by quantifying them with a questionnaire about teachers' motivation and then correlating the results with the quality of their teaching. Kunter et al. performed this inquiry with school maths teachers. ${ }^{25}$ They drew a link between the teachers' enthusiasm for the subject matter and teaching process with their performance in the classroom, as measured by self-evaluations and student ratings. They found that teachers who were more enthusiastic about the teaching process displayed a higher degree of teaching proficiency, both in student and selfevaluations, while the teachers' enthusiasm for the subject of mathematics only positively correlated to reports in the teachers' self-evaluations, but not to the student ratings. This finding may be different for teachers in higher education (of health professionals). However, there is evidence in the literature suggesting that university students value teaching skills and ability to transmit knowledge more than the academic status of the teacher. ${ }^{26,27}$ If it were demonstrated that effective teaching requires a well-balanced interest in the subject matter and in the desire to see students develop, an attempt could be made to measure them separately for each teacher and strengthen the weaker of the two through faculty development measures.

In this study, participants strongly emphasized learning through teaching and, in this way, integrating new knowledge into their field of expertise. The role of the physicians own learning through teaching has been described in a recent qualitative study by Wenrich et al. ${ }^{28}$ Their data suggest that teaching pre-clerkship students at a patient's bedside has a profoundly positive impact on the teacher's own clinical skills. Similarly, Hartley et al. found that general practitioners who teach clinical skills to undergraduate medical students enhance their own morale and clinical practice. ${ }^{17}$ It would be instructive to further investigate how the teaching of didactical lectures may also influence the professional practice of health professionals. Our findings suggest that it may do so. If that could be clearly shown, communicating this aspect of teaching to the faculty can help health professionals to appreciate the value of teaching.

The two other themes identified that suggest an increase in intrinsic motivation to teach are the interest in establishing teacher-student rapport and the importance of students' (positive) feedback. While establishing teacher-student rapports may contribute to a sense of acceptance and being valued by others (which is in line with SDT's assumption that intrinsic motivation is fostered by satisfying the need for relatedness), receiving students' feedback validates the success of the teacher's performance. This again is in line with the prediction of SDT that satisfying the need for competence, in this case having the feeling of being an effective teacher, is important for health professionals in order to generate and maintain an intrinsic motivation to teach. This explains why didactic lecturing to large groups of students is often - as in this study - described as demotivating, since here both establishing teacher-student rapport and receiving feedback from the students are difficult to achieve. In institutions where the curriculum includes such a teaching environment, faculty development initiatives should propose strategies to foster teacher-student rapport and informal student feedback. For example, the implementation of mentoring programs that allow teachers to follow students over long periods of time makes student development visible and should enhance faculty motivation to engage in education. In large class teaching the strategy of selecting two student representatives to give feedback to the lecturer in a face-to-face meeting after class can be proposed. ${ }^{6}$

\section{Limitations and implications}

This study has several limitations. As the sample size was small, a theoretical saturation of data cannot be expected. A larger sample may have revealed additional themes and subthemes, although it was felt that the emerging interpretive themes were well supported by the data. Furthermore, the study took place in a one institutional setting and participants were not representative of all health professionals teaching at this institution. This may limit the generalizability of the results. However, the data revealed a high degree of consensus between the participants, and there seems to be no reason to suspect that the intrinsic motivation to teach should differ between institutions. It could also be argued that there might be a variation in factors influencing teaching motivation across different health professions; but again, we see no reason why the satisfaction derived from teaching should differ between professions and, therefore, believe that the range of the participants' professional occupations in this study (eight participants represented four different professions) adds credibility to the findings. However, the question remains as to how the selective sampling of highly motivated teachers (who attended the pedagogical sessions) might have influenced 
the results. Motivated teachers who did not attend may have been eliminated. In addition, it may yield interesting information to interview 'negative cases' of less motivated teachers. In this study we decided to use a purposive opportunity sampling based on the desire to find highlymotivated individuals as 'key informants'. In-depth interviews were the selected method of data collection because we aimed at eliciting individual experiences. As a next step however, it could prove worthwhile to present and discuss the findings of this study in focus groups.

Further research is needed to validate our findings with larger sample sizes, and more diverse samples and across various institutional settings. We suggest that research then focuses on quantifying a teacher's level of motivation in order to examine the relationship between the level of motivation and the factors that affect that motivation. Essential questions to be addressed are how those factors relate to instructional performance and ultimately to student outcome, and how the significance of those factors changes over time in a teaching career.

\section{Conclusion}

This study has addressed a topic where research-based knowledge is limited: the intrinsic motivation to teach. Four themes that suggested an internal desire to teach were identified: Interest in the subject matter, interest in students' development, interest in establishing teacher-student rapport, and the importance of students' feedback. The findings contribute to a deeper understanding of the internal desire of health professionals to engage in teaching and constitute a starting point for developing further research to explore these processes more fully. A better understanding of the factors that enhance a teacher's motivation can help to optimise educational environments.

\section{Acknowledgements}

We would like to acknowledge Philip Darbyshire and Wim Gijselaers for their comments and suggestions on this manuscript. We would also like to thank all of the health professionals who participated in this study.

\section{Conflicts of Interest}

The authors declare that they have no conflict of interest.

\section{References}

1. Dörnyei Z. Teaching and researching motivation. Harlow: Longman; 2001.

2. Woolfolk Hoy A. What motivates teachers? Important work on a complex question. Learning and Instruction. 2008;18:492-498.

3. Fry H, Ketteridge S, Marshall S. A handbook for teaching and learning in higher education. Enhancing academic practice. $2^{\text {nd }}$ ed. London and New York: RoutledgeFalmer; 2003.

4. Bligh DA. What's the use of lectures? San Francisco: Jossey-Bass; 2000.

5. Ramsden P. Learning to teach in higher education. London: Routledge; 1992.

6. McKeachie W, Svinicki M. Teaching tips. Strategies, research, and theory for college and university teachers. $12^{\text {th }}$ ed. Boston: Houghton Mifflin Company; 2006.

7. Hoban JD, Cariaga-Lo L, Bennett BA, Ernest JM, Vanderweide SA, Harrington ME. Incentives for teaching. Academic Medicine. 1996;71(2): 106-107.

8. Gerrity MS, Pathman DE, Linzer M, Steiner BD, Winterbottom LM, Sharp MC, et al. Career satisfaction and clinician-educators. The rewards and challenges of teaching. Journal of General Internal Medicine. 1997;12 (Supplement 2):S90-97.

9. Levy B, Gjerde CL, Albrecht LA. The effects of precepting on and the support desired by community-based preceptors in Iowa. Academic Medicine. 1997;72(5):382-384.

10. Hill N, Wolf KN, Bossetti B, Saddam A. Preceptor appraisal of rewards and student preparedness in the clinical setting. Journal of Allied Health. 1999;28:86-90.

11. Kumar A, Kallen DJ, Mathew T. Volunteer faculty: what rewards or incentives do they prefer? Teaching and Learning in Medicine. 2002;14(2):119-123.

12. Starr S, Ferguson WJ, Haley H-L, Quirk M. Community preceptors' views of their identities as teachers. Academic Medicine. 2003;78(8):820825 .

13. Wright SM, Beasley BW. Motivating factors for academic physicians within departments of medicine. Mayo Clinic Proceedings. 2004;79(9): $1145-1150$.

14. Scott I, Sazegar P. Why community physicians teach students (or not): Barriers and opportunities for preceptor recruitment. Medical Teacher. 2006;28(6):563-565.

15. Latessa R, Beaty N, Landis S, Colvin G, Janes C. The satisfaction, motivation, and future of community preceptors: the North Carolina experience. Academic Medicine. 2007;82(7):698-703.

16. Dahlstrom J, Dorai-Raj A, McGill D, Owen C, Tymms K, Watson DA. What motivates senior clinicians to teach medical students? BMC Medical Education. 2005;5(27):27.

17. Hartley S, Macfarlane F, Gantley M, Murray E. Influence on general practitioners of teaching undergraduates: qualitative study of London general practitioner teachers. British Medical Journal. 1999;319:1168-1171.

18. Foley R, Yonke A, Smith J, Roe B, Vance J. Recruiting and retaining volunteer community preceptors. Academic Medicine. 1996;71(5):460-463.

19. Vath BE, Schneeweiss R. Volunteer physician faculty and the changing face of medicine. Western Journal of Medicine. 2001;174:242-246.

20. Ryan RM, Deci EL. Intrinsic and extrinsic motivations: classic definitions and new directions. Contemporary Educational Psychology. 2000;25:54-67.

21. Ten Cate TJ, Kusurkar RA, Williams GC. How self-determination theory can assist our understanding of the teaching and learning processes in medical education. AMEE guide no. 59. Medical Teacher. 2011;33:961973.

22. Deci EL, Kasser T, Ryan RM. Self-determined teaching: opportunities and obstacles. In: Bess JL, editor. Teaching well and liking it motivating faculty to teach effectively. Baltimore: the Johns Hopkins University Press; 1997. p. 57-71.

23. Ryan RM, Deci EL. Self-determination theory and the facilitation of intrinsic motivation, social development, and well-being. American Psychologist. 2000;55(1):68-78.

24. Strauss A, Corbin J. Basics of qualitative research: techniques and procedures for developing grounded theory. 2nd ed. Thousand Oaks, CA: Sage Publications; 1998.

25. Kunter M, Tsai Y-M, Klusman U, Brunner M, Krauss S, Baumert J. Students' and mathematics teachers' perception of teacher enthusiasm and instruction. Learning and Instruction. 2008;18:468-482.

26. Sander P, Stevenson K, King M, Coates D. University students' expectations of teaching. Studies Higher Education. 2000;25(3):309-323.

27. Miron M, Segal E. "The good university teacher" as perceived by the students. Higher Education. 1978;7(1):27-34.

28. Wenrich MD, Jackson MB, Ajam KS, Wolfhagen IH, Ramsey PG, Scherpbier AJ. Teachers as learners: the effect of bedside teaching on the clinical skills of clinician-teachers. Academic Medicine. 2011;68(7):846-852. 